\title{
XLI. A new form of electric chronograph
}

\author{
Rev. Frederick J. Smith M.A.
}

To cite this article: Rev. Frederick J. Smith M.A. (1890) XLI. A new form of electric chronograph , Philosophical Magazine Series 5, 29:180, 377-383, DOI: 10.1080/14786449008619956

To link to this article: http://dx.doi.org/10.1080/14786449008619956

$$
\text { 曲 Published online: } 08 \text { May } 2009 .
$$

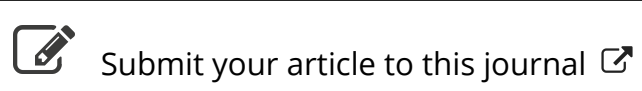

Џll Article views: 2

Q View related articles ¿ 
LONDON, EDINBURGH, AND DUBLIN

\title{
PHILOSOPHICAL MAGAZINE
}

\author{
AND \\ JOURNAL OF SCIENCE.
}

[FIFTH SERIES.]

$M A Y 1890$.

XLI. A New Form of Electric Chronograph. By Rev. Frederick J. Smith, M.A., Millard Lecturer in Mechanics and Physics, Trinity College, Oxford *.

[Plate IX.]

D URING the last two years a research has been carried on by me on the subject of the acceleration-period of explosions $\dagger$. In order to deal with the time-measurements which arose out of the investigation, it was found necessary to devise a chronograph which would register a large number of events following each other after small periods of time. As the chronograph used in these experiments has been found to be of use in other branches of scientific work, viz. in determining the velocity of shot, and many physiological timemeasurements, I beg to offer an account of its construction and use to the readers of the Philosophical Magazine. The instrument has been called the Electric Tram Chronograph, because the moving surface is carried upon wheels running on rails.

The instrument has, in common with other forms of timemeasuring instruments, a moving plate on which traces are made by means of electromagnetic styli. In other respects it greatly differs from other forms of time-measuring instruments.

In order that an electric chronograph may be of general

* Communicated by the Author.

$\uparrow$ Proceedings of the Royal Society, xlv. p. 451.

Phil. Mag. S. 5. Vol. 29. No. 180. May 1890. $2 \mathrm{G}$ 
use, several conditions have to be complied with; some of these are as follows :-

(1) The moving surface on which the time-traces are made should be both long and wide. It should be long, so that periods greatly differing in their duration may be recorded on the same surface close together. It should be wide, so that a large number of time-determinations may be made and compared side by side on the same plate.

(2) The experimentalist should be able to vary the velocity of the moving surface.

(3) The surface should so move that all the time-traces may be in straight lines, and the velocity of the surface should be uniform during an experiment. The necessity for uniform movement is forced upon one by the experience of the diffculty found in subdividing a tuning-fork trace as recorded by a pendulum-chronograph. When a time-record is made on a surface which is moving at a uniform velocity, the difficulty of accurately subdividing a single vibration at once disappears.

(1) The marking-points of the electromagnetic styli, actuated by springs, when released from an electromagnet, should make a sharp and definite mark ; also the time between the breaking of the circuit and the marking should be as short as possible, and it should be constant in value.

These ends have been attained in the following manner :To a vertical carriage, running upon wheels, between two rails, a sheet of smoked glass is fixed. The carriage is impelled by means of a cord attached to a weight; after the weight has acted upon the carriage through a certain length of fall it is arrested, and the carriage moves with the velocity it has attained: this velocity is found to be practically constant for the whole length of the trace. It will be noticed that this arrangement embodies the principle of the Atwood machine. It will also be noticed that the impulse given by means of the falling weight gives a maximum velocity at the point where its pressure is taken off. With respect to pressure given by a spiral spring, as used in the well-known shooter employed in physiological work, exactly the opposite of this takes place. The writing-points of the electromagnetic styli and the tracingpoint of the tuning-fork are placed so as to mark the moving surface.

The distance between the markings of the styli is obtained in terms of the length of the vibrations of the fork : from this the time between two or more markings is determined. This will become clear from the consideration of the following detailed deseription of the instrument. 
The rails.-Two steel rails, A B and C D, each 2 metres long (Plate IX. fig. 1), are attached to three cast-iron standards : two of these, $\mathrm{M}$ and $\mathrm{N}$, are shown. Fach standard is furnished with two levelling-screws. The upper rail is adjustable, so that it may be placed parallel to the bottom rail, and at a correct distance from it for the width between the wheels of the carriage. (The rails are slightly inclined from D to C.)

The carriage, $\mathrm{E} \mathrm{F}$, is built up of bars (which are not shown) so as to be both light and rigid. It runs upon three wheels, each wheel being carried on two steel points; the points are adjustable, so that the face of the carriage can be placed parallel to the plane of the rails. To the front of the carriage a sheet of smoked glass is fixed with clips and screws. The carriage is furnished with a catch which engages with a detent at $\mathrm{H}$; by this it is held back against the pull due to the weight, $W$, nntil required to run past the styli. A projection at the back of the carriage engages with a leather brake-band.

The lrake.-A band of leather, $\mathrm{L}$, is fixed to the standard, $M$, and also to a strong spiral spring at the back of the upper rail : the projection previously mentioned rubs under the band and brings the carriage to rest without any concussion.

The weight.-A gut-band or cord, passing over the pulleys, $\mathrm{Q}, \mathrm{P}, \mathrm{R}$, is fixed at $\mathrm{G}$; it is provided with a small ball which engages with a fork fixed to the back of the carriage. The weight impels the carriage until it is arrested by contact with an adjustable table $\mathrm{T}$; the carriage then runs on with the veloeity acquired. The velocity is found to be practically uniform throughout the whole length of a time-trace. The cord, if free, has a velocity approximately double that of the drivingweight.

Electromagnetic styli.-These are shown at AA (fig. 2). An electromagnet of peculiar construction is mounted upon a brass plate, which carries a T-shaped lever ; to this a writingpoint of aluminium, mica, or parchment-paper is attached. The lever is held by the electromagnet, as long as a current is acting upon it, against the pressure of a spring : when the current is broken the lever rises and gives its marking. The electromagnet is so constructed and wound that its period of "latency" is exceedingly small, and also constant within close limits. By means of a flat rectangular spring the stylus is attached to a pillar furnished with a sliding-holder B : each stylus can be easily adjusted to a vertical line for experiments in which a large number of markings are required in succession.

The pillar-support.-It has been found that, unless the support of the styli is free from vibration, the trace produced by them is not worth much. The pillar used in connexion with 2 G 2 


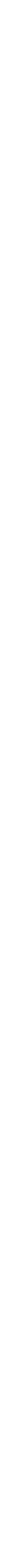


the instrument consists of a heavy iron casting, C C (fig. 2) fitted with a slide, $B$, the slide can be raised or lowered by means of a screw with a milled head, the styli are attached to the slide B. By raising the slide after each experiment a large number of traces can be made side by side, and by the addition of an extra carrier as many as 10 styli can be carried. The pillar can be rotated on a triangular base, which is supported upon three levelling-screws. The screws rest after the method of Sir W. Thomson, viz. in a hole, a groove, and on a plane, on the slab which supports the chronograph. The points of the styli are adjusted to the face of the glass by a screw S. A simple pillar, $A^{\prime}$, can also be used when only one set of traces is required.

The tuning-fork.-A tuning-fork $\mathrm{T}$ is carried upon a pillar, which slides upon a block in which a V-groove is cut; a screwstop limits its position against the glass. The fork may be driven electrically, or it may be excited otherwise. In the experiments on explosions the fork was started by means of a wedge, which kept the prongs apart, being suddenly withdrawn by means of an electromagnet.

The latency of electromagnetic styli.-While going through a large number of papers upon investigations in which electromagnets were used for measuring time, it was found that in nearly all cases it had been assumed that the armature of an electromagnet was detached at the instant of the circuit being broken; also, that in two instruments of similar construction the armature was released at the same instant. Several electromagnets of chronographs were examined: in some cases, where much iron was used in the cores, the time between breaking and release of the armature was as much as 0.04 second; also two apparently similar shaped electromagnets with similar windings, equal currents being used, differed in their action by some hundredths of a second. The experiments showed in a very definite manner that some electromagnets were not to be depended upon for close and accurate work.

In order to produce an electromagnetic stylus free from these evils a large number of experiments were gone through on the relative proportions of the cores and their yoke, also upon the winding. It was found that the yoke should be made large as compared with the cores; the dimensions finally adopted were:-

Cores . . . . 2 millim. diam. ; 10 millim. long.

Yoke . . . 20 millim. $\times 5$ millim. $\times 5$ millim.

The method of measuring the period of delay spoken of, which may be called the latency of the stylus, is as follows, it 
may be taken as an example of the way in which the instrument is used (see fig. 3) :-A piece of warm glass is smoked over the flame of a paraffin lamp furnished with a wide wick; it is then attached to the carriage, and the stylus to be tested is adjusted to the surface of the glass, also the tuning-fork is adjusted so that its writing-point lightly touches the glass; an electric circuit is then completed through the break I (fig. 2), and the stylus prepared for giving a signal. The carriage is then brought slowly past the stylus, the result of which is that a vertical mark I $\mathrm{H}$ (fig. 3) is produced; the carriage is then held back by the detent, the stylus is again prepared, by the armature being caused to touch the poles of the electromagnet, the fork is excited, and the carriage released : the markings K N M L and A B are then produced. The tuning-fork point is brought against the glass so that a straight line may be drawn by it, the intersections of this with the curved line determine the limits of any vibration. The length of the traverse I N, duly turned into time, is the latency of the stylus. Lines are drawn by a needle's point through the points I and $\mathbf{N}$, cutting $\mathrm{A} \mathrm{B}$ in $\mathrm{E} \mathrm{F}$; the value of $\mathrm{E} F$ is then determined by means of a micrometer microscope, constructed as shown in fig. 4. In all cases of estimating time the fork is excited for each observation, the writing-point of the fork being placed vertically above the w'riting-points of the styli, so that the velocity of the moving surface is common to both the fork and the stylus. The needle-point for scribing the vertical lines is carried on a kind of dividing-engine. The styli are found to have a latency of almost perfect constancy, its value being 0.0003 second. The first stylus constructed by me, and used in the Physiological Laboratory of the University, was not proportioned as the later ones have been; it was tested by Prof. G. F. Yeo, and his result published in the 'Journal of Physiology,' vol. ix. nos. 5 and 6, gave as a value of latency 0.00062 sec. The improved result, viz. 0.0003 , has been arrived at by a careful selection of the iron used, and a modification of the winding of the bobbins; by the reduction of the latency the marking is rendered much more definite and readable. The two facsimile tracings (fig. 5) show the nature of the markings of a time-trace of a slow explosive wave. $\dot{B} \dot{A}$ or BA equals $0.00227^{\prime \prime}$.

The micrometer-microscope is mounted on a bridge E F (fig. 4) attached to an inclined table A B; it is carried by means of a slide, which permits movement parallel to the trace which is put under it; the slide is moved by a screw having 40 tnreads to the inch; the screw has a micrometer-head divided into 25 large divisions, each of these is again divided into 4 parts, so 
that $\frac{1}{40} \times \frac{1}{100}=\frac{1}{400}$ of an inch can be read with ease. The microscope is furnished with a fine fibre which is brought over the trace to be measured; a rod of rectangular section $\mathrm{H} \mathrm{K} \cdot$ is attached to two links or rods, $\mathrm{L} \mathrm{H}, \mathbf{M ~ K}$; the links being equal and moving about the points $M$, cause the rod to move always parallel to itself; upon the rod the trace rests; any part of the trace can be brought under the microscope. The markings appear as rather wide lines of light; a V-shaped scale in the field of the instrument enables one to bisect these lines. Fig. 3 gives an illustration of its use. The centre of the field is brought over $\mathrm{C}$, the index of the micrometer-screw being at zero; then the microscope is moved by the screw till the centre coincides with $\mathrm{D}$. The length $\mathrm{CD}$ is then recorded, let it be $\mathrm{L}$; then the micrometer is brought to zero again, and $E$ is brought under the centre, and $E F$ is then measured in the same manner as CD, let it be $l$; then, if $x$ denote the time of traverse over $\mathrm{EF}$, and $t$ the time of one vibration,

and

$$
\mathrm{L}: l:: t: x,
$$

$$
x=\frac{l t}{\mathrm{~L}} \text {. }
$$

Fractions of a vibration can thus be easily estimated with great accuracy. This proportional method of subdividing the vibrations depends upon the fact that the velocity of the carriage is practically uniform.

The method of preserving time-traces.-After the smoked glass has received records of time-traces it may be preserved by being varnished. It is a somewhat difficult matter to cover a smoked plate with photographic varnish without making either streaks on the plate or removing a good deal of the carbon surface; but if the varnish be diluted with about 25 times its volume of strong methylated spirit, it may be poured over the plate without injuring the trace. When it has dried off ordinary photo-varnish may be applied without any risk of doing harm. In the first case the plate should be cold, in the second it may be a little heated before a fire previous to the application of the thicker varnish. The traces can then be used as negatives to print from in the usual way. Eastman's bromide-paper in rolls has been found to be most convenient for reproducing the traces. One of these is shown at fig. 5. The lines are thicker than those usually made, as a thicker deposit of carbon was used to get a very dense negative to make a print for this communication to the Philosophical Magazine. 
I wish to add that Mr. A. W. Price has greatly assisted me in the manufacture of the new instrument. The method of increasing the velocity of the carriage by the introduction of a pulley attached to the driving-weight is due to him.

XLII. On the Electrical and Chemical Properties of Stannic Chloride; together with the Bearing of the Results therein obtained on the Problems of Electrolytic Conduction and Chemical Action.-Part I. Experimental Observations. Part II. Theoretical Considerations. By WARD CoLdRIDGe, B.A., Scholar of Einmanuel College, Cambridge*.

\section{INTRODUCTION.}

THE germ from which this work has been developed was 1 found in Faraday's statement that Stannic Chloride is a nonconductor. In the first instance this led to an investigation of the lower limit of its conductivity ; the result which is here recorded was submitted to the Meeting of the British Association at Bath in 1888 by my friend Mr. W. N. Shaw, Fellow of Emmanuel College, who experimented with me on this point: in the second instance I examined the condition requisite for the development of electrolytic power; the results obtained are here for the first time recorded.

It is claimed that, by taking advantage of the suitable chemical and physical properties of stannic chloride, a definite advance has been made towards the resolution of the ambiguous statement that "heterogeneity is necessary for the development of electrolytic power," and that the results of Part I. throw light on the nature of an effective impurity, and in so striking a manner exhibit the parallelism between the chemical and electrical properties that the conviction arises of an ultimate explanation common to both. I have endeavoured to arrive at a single consistent view which shall explain the phenomena observed; and in "stating the idea I have carefully abstained from wandering into disquisitions on other ideas, as that of Arrhenius's vagrant atoms, which, according to my notion of the stability of the fundamental chemical molecule, are untenable.

The field of research from which these results have been gathered is a fertile one. Incidentally some opportunities are mentioned : I am conscious that pure pentachloride of antimony, inter alia, would yield interesting results.

With much pleasure I acknowledge my indebtedness to

* Communicated by the Author 